\title{
MATRICS: A Method for Aggregating The Reporting of Interventions in Complex Studies
}

\author{
Kymberley Thorne ${ }^{1 *}$, Gabi S Jerzembek², Wai-Yee Cheung ${ }^{1}$, David Cohen ${ }^{3}$, Hayley A Hutchings', \\ Frances L Rapport ${ }^{1}$, Anne C Seagrove ${ }^{1}$, John G Williams ${ }^{1}$, Ian T Russell ${ }^{1}$ \\ From Clinical Trials Methodology Conference 2011 \\ Bristol, UK. 4-5 October 2011
}

\section{Background}

There are few rigorous methods for combining qualitative and quantitative findings from studies with complex interventions using multiple research methods and giving appropriate weight to each without introducing bias to the overall conclusions.

We developed a Method for Aggregating The Reporting of Interventions in Complex Studies (MATRICS) for the ENIGMA study (Evaluating Innovations in Gastroenterology by the NHS Modernisation Agency) - a multicentre, mixed-methods study to evaluate the impact of the Modernising Endoscopy Services programme [1], funded by the UK National Institute for Health Research (NIHR SDO ref 08/1304/46).

\section{Method}

We developed a template that requires researchers to follow the steps outlined below:

1. List the types of effects identified by the study (from the aims objectives and outcome measures), and divide them between effects on: sample population (eg patients, carers); on the specialty being investigated (eg intensive care, outpatients) and on the rest of the organisation and society and give each a unique number.

2. List the methods used to explore each effect listed in step 1 and give each a unique letter (eg GP interviews, patient questionnaires, routine data linkage).

3. Create an alphanumeric code by cross matching the effects identified and the methods used to investigate them (eg patient satisfaction " 1 " was investigated using a patient questionnaire " $\mathrm{A}$ " $=1 \mathrm{~A}$ ).

\footnotetext{
* Correspondence: k.thorne@swansea.ac.uk

${ }^{1}$ Centre for Health Information Research and Evaluation, Grove Building, College of Medicine, Swansea University, Singleton Park, Swansea, SA2 8PP, UK

Full list of author information is available at the end of the article
}

4. List the explicit findings of the study and label them using the alphanumeric code (eg "patients were dissatisfied with waiting times - A1").

5. Synthesise all consistent findings and list their alphanumeric codes alongside to characterise mutually confirmatory findings. Synthesis is best done independently by at least two researchers.

6. Reorder all contradictory findings and their alphanumeric codes adjacent to one another to better illustrate all conflicting findings.

\section{Findings}

The MATRICS tool greatly facilitated the unbiased factual reporting of findings from multiple methods for ENIGMA [1]. Additionally, it was most beneficial for the qualitative synthesis of the findings of ENIGMA, a study unsuited to formal cost-benefit analysis, like most in this field.

We have also applied the MATRICS successfully to other complex studies using multiple methods.

\section{Discussion}

If the experience of the study team regarding the MATRICS approach to synthesising results in complex studies is reflected by others, it could provide a formal structure for reporting the results of complex and/or multiple-method studies. Further application of this methodology will provide evidence of whether this reporting tool will improve a reader's understanding of a study and its findings.

\section{Author details}

${ }^{1}$ Centre for Health Information Research and Evaluation, Grove Building, College of Medicine, Swansea University, Singleton Park, Swansea, SA2 8PP, UK. ${ }^{2}$ Institute of Health Service Effectiveness (IHSE), Aston University Business School, Aston Triangle, Birmingham, B4 7ET, UK. ${ }^{3}$ Faculty of Health Sport and 
UK.

Published: 13 December 2011

\section{Reference}

1. Williams JG, Cheung WY, Cohen D, Hutchings H, Jerzembek G, Rapport F, Russell IT, Seagrove AC, Thorne K: Evaluating innovations in the delivery and organisation of gastroenterology services initiated directly or indirectly by the Modernising Endoscopy Services programme of the NHS Modernisation Agency. London: National Institute for Health Research Service Delivery and Organisation Programme; 2008 [http://www.sdo.nihr.ac uk/files/project/46-final-report.pdf].

doi:10.1186/1745-6215-12-S1-A147

Cite this article as: Thorne et al: MATRICS: A Method for Aggregating The Reporting of Interventions in Complex S1):A1 $\overline{4} 7$.

Submit your next manuscript to BioMed Central and take full advantage of:

- Convenient online submission

- Thorough peer review

- No space constraints or color figure charges

- Immediate publication on acceptance

- Inclusion in PubMed, CAS, Scopus and Google Scholar

- Research which is freely available for redistribution

Submit your manuscript at www.biomedcentral.com/submit
( Biomed Central 